\title{
Caracterización geoquímica de las sales procedentes de deyecciones de palomas en patrimonio monumental. Iglesia de El Salvador (Úbeda, Jaén)
}

\author{
Pedro Luis López Julián, Josep Gisbert Aguilar, José Ángel Pérez Benedicto, Ángel Salesa \\ Bordonaba, Manuel Delgado del Valle y Juan Carlos Sánchez Catalán
}

\begin{abstract}
Resumen El deterioro ocasionado en el patrimonio histórico a consecuencia de las sales procedentes de deyecciones de palomas debe ser adecuadamente identificado y localizado. La realización de mapas de conductividad superficial en los paramentos, la extracción de sales mediante apósitos de celulosa y su análisis químico, y la posterior evaluación geoquímica constituyen la mejor combinación metodológica disponible para identificar la procedencia de este tipo de sales. A partir de un caso práctico se ha podido concluir que, en las zonas donde son patentes estas concentraciones salinas y sus consecuencias, predominan las sales de $\mathrm{KNO}_{3}$, pero donde los precipitados están en una fase incipiente de acumulación, es posible identificar dicho proceso activo por el predominio de $\mathrm{Na}^{+}, \mathrm{K}^{+}$, $\mathrm{NO}_{3}^{-}$y $\mathrm{Cl}^{-}$en las extracciones salinas obtenidas mediante apósitos de celulosa. La correcta identificación del origen de las sales en los paramentos permite diseñar de forma eficiente las actuaciones de limpieza y mantenimiento.
\end{abstract}

Palabras clave: deyecciones, sales, apósitos de celulosa, geoquímica, proporciones iónicas, restauración

\section{Geochemical characterization of salts generated from bird droppings on historic heritage. The church of El Salvador (Úbeda, Jaén)}

Abstract: Damage on historic heritage caused by salts related to bird droppings should be properly identified and located. The best combination of methodologies in order to identify the source of such type of salts consist of: mapping surface conductivity of walls, extracting salts using cellulose poultices and evaluating solutions geochemistry. In this case study, we concluded that $\mathrm{KNO}_{3}$ was the predominant salt in those areas where salt efflorescence caused larger damage. Conversely, $\mathrm{Na}^{+}, \mathrm{K}^{+}, \mathrm{NO}_{3}^{-}$and $\mathrm{Cl}^{-}$were predominant in areas where salts were at an early stage of crystallization. The correct identification of the origin of salts in walls enables efficient planning for intervention for cleaning and maintenance of heritage.

Keyword: droppings, salts, paper pulp poultices, geochemistry, ionic ratios, restoration

\section{Identificação geoquímica de sais gerados por excrementos de pássaros em património monumental. A Igreja de El Salvador (Úbeda, Jaén)}

Resumo: Os danos causados ao património histórico como resultado de sais com origem em excrementos de aves devem ser adequadamente identificados e localizados. A realização de mapas de condutividade de superfície nas paredes, a extração de sais através de pachos de celulose e a sua análise química, e a posterior avaliação geoquímica, constituem a melhor combinação metodológica disponível para identificar a origem deste tipo de sais. A partir de um caso prático concluiu-se que, nas zonas em que estas concentrações salinas e as suas consequências são visíveis, predominam os sais $\mathrm{KNO}_{3^{\prime}}$ mas onde os sais estão numa fase incipiente de acumulação é possível identificar o referido processo ativo pela predominância de $\mathrm{Na}^{+}, \mathrm{K}^{+}, \mathrm{NO}_{3}{ }^{-}$e $\mathrm{Cl}^{-}$nas extrações salinas obtidas por meio de pachos de celulose. A identificação correta da origem dos sais nas paredes permite planear com eficiência as ações de limpeza e manutenção.

Palavras-chave: Dejetos, sais, pachos de celulose, geoquímica, proporções iónicas, restauro 


\section{Introducción}

Los problemas asociados a la acumulación de sales en el patrimonio monumental son muy frecuentes, constituyen una de las principales causas de deterioro de fábricas pétreas en edificación histórica y han sido estudiados desde hace ya varias décadas (Schaffer, 1932; Winkler, 1973). Las sales aparecen como consecuencia de los procesos de disolución, transporte y precipitación que tienen lugar sobre y a través de los distintos elementos constructivos de los edificios, y tienden a acumularse en aquellas zonas donde el agua se evapora, dejando su carga química precipitada.

El agua que circula sobre y a través de los elementos constructivos de un monumento puede proceder de tres orígenes bien diferenciados:

-Del exterior, procedente de precipitaciones que inciden directamente sobre los paramentos o que no son adecuadamente canalizadas por los elementos de desagüe.

-Del subsuelo, por ascenso capilar a través de los elementos basales en contacto con el terreno.

-Finalmente, por condensación de humedad ambiental, tanto exterior como interior.

Este volumen de agua, variable en el tiempo y en el espacio, se desplazará en función de la gravedad, de las fuerzas de succión capilar y, también, por la desigual distribución de humedad en las distintas zonas de los monumentos. La entrada de agua procedente de precipitaciones tiene una componente principal vertical descendente a causa de la gravedad, y otra componente desde el exterior del edificio hacia el interior. Por su parte, la entrada de agua por capilaridad tiene una componente vertical ascendente que progresa hasta que la fuerza de succión capilar se equilibra con la gravedad. En cada momento, el agua que empapa los elementos constructivos tiende a equilibrarse además con la humedad ambiental existente en cada zona (cediendo o absorbiendo vapor de agua), definiéndose de este modo unas pautas de flujo que se dirigen hacia las áreas de menor humedad ambiental y satisfaciendo en cada caso tanto el efecto de la gravedad como la succión capilar.

La cristalización de sales en monumentos se puede producir sobre la superficie de los paramentos en forma de eflorescencias, o bien como subeflorescencias cuando dicha precipitación salina se produce en el interior de rocas y morteros (López-Acevedo et al. 2007). Los mecanismos de deterioro se relacionan con las condiciones de precipitación de las sales en el medio poroso constituido por los materiales constructivos (Flatt, 2002), y existe un claro control de la distribución de tamaños de la red de poros sobre la ubicación de las sales precipitadas (Blanco et al. 2010). En cualquier caso, el proceso repetitivo de transporte de sales en disolución y su precipitación por evaporación lleva a un deterioro progresivo de los materiales constructivos, llegando incluso a su fragmentación física, con los consiguientes problemas tanto de pérdida de elementos de valor artístico como de seguridad en el servicio público de la instalación. Las intervenciones en patrimonio suelen acometerse cuando esta fase avanzada de deterioro ya se ha manifestado a través de fenómenos tales como desplacado, disgregación o arenización, y entonces la solución pasa ineludiblemente por un saneamiento del material afectado, operación que puede abarcar desde una limpieza superficial hasta incluso la sustitución de los volúmenes más dañados, con la consiguiente pérdida de patrimonio con valor histórico-artístico. De todo ello se deduce la importancia de una detección temprana de las zonas de acumulación salina que puedan llegar a producir un deterioro importante del patrimonio.

Una fuente importante de las sales puede proceder del lavado de acumulaciones de deyecciones de aves en zonas de cubiertas o salientes elevados (Grossi y Esbert 1994; Garabito et al. 2013), habiéndose puesto de manifiesto su potencial importancia desde el punto de vista experimental (Gómez-Heras et al. 2004). Algunos trabajos más recientes abordan los mecanismos asociados a los procesos de deterioro provocados por dichas acumulaciones (Dyer, 2017; Spennemann et al., 2017), y en otros se tienen en consideración, pero superpuestos a otros mecanismos adicionales causantes de patologías (Giustetto et al., 2017).

El presente trabajo desarrolla este aspecto desde una perspectiva eminentemente aplicada y con un interés evidente para los estudios previos a las actuaciones de restauración. Se presentan aquí los resultados obtenidos en la investigación desarrollada sobre un monumento afectado por precipitación de sales, la iglesia de El Salvador (Úbeda), a fin de determinar los efectos de las aguas que lavan acumulaciones de deyecciones de aves y que acaban movilizando su carga salina y contribuyendo así al deterioro del patrimonio. También se valora la importancia de esta información a la hora de realizar las recomendaciones más adecuadas para la restauración y mantenimiento de los monumentos.

\section{- Caso de estudio}

El monumento que sirve de base para este estudio es la iglesia de El Salvador de Úbeda (Jaén), iglesia panteón del palacio de D. Francisco de Cobos, diseñada por Diego de Siloé en la década de 1530 y construida por Andrés de Vandelvira. Se trata de un monumento funerario con una portada plateresca monumental, con representaciones de la Transfiguración y de escenas de la mitología aplicadas a la simbología cristiana [figura 1]. La cabecera, con planta centralizada cubierta por cúpula, sigue el modelo clásico del Panteón de Roma, mientras que la nave longitudinal con capillas en nicho, el de basílica al modo romano. La iglesia fue declarada monumento histórico-artístico en 1931, y forma parte del conjunto monumental renacentista de la ciudad de Úbeda que, junto con el de su vecina Baeza, fue declarado Patrimonio de la Humanidad por la Unesco en 2003. 
La fachada oeste de El Salvador presenta una imponente portada renacentista que sigue una estructura de gran arco de triunfo, con diferentes niveles decorativos y de calidad escultórica. Por otra parte, las portadas laterales presentan arcos de triunfo de un plateresco avanzado y culto, profusamente decoradas escultóricamente con toda probabilidad por Esteban Jamete.

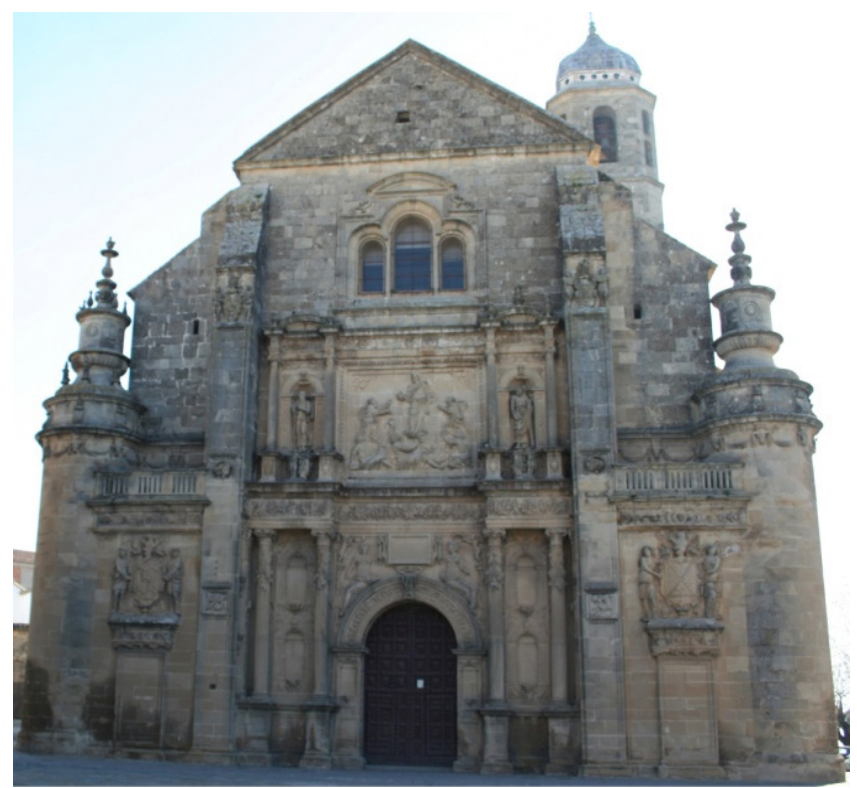

Figura 1.- Fachada oeste de la iglesia de El Salvador (Úbeda, Jaén)

Los principales materiales constructivos empleados en la fachada son sillares de roca arenisca (arenita híbrida según la clasificación de Zuffa 1980), constituida por clastos carbonatados y cuarzosos y con una porosidad variable (entre 3 y $20 \%$ ), habiéndose empleado tanto morteros de cal como de yeso.

Parte de la información manejada en este artículo procede del informe realizado a petición de la Diputación Provincial de Jaén para estudiar tanto los materiales pétreos empleados en su construcción como las patologías existentes (Equipo Arbotante 2009). El presente artículo incluye parte de la amplia información obtenida durante la realización de dicho estudio, aunque el objetivo específico aquí buscado es el de desarrollar un método para determinar la contribución de las afecciones provocadas por las deyecciones de palomas en el patrimonio monumental, dentro del conjunto de patologías debidas a procesos de salinización.

\section{Metodología}

La obtención de la información de partida necesaria para este estudio ha implicado la adquisición directa de datos sobre los paramentos, el muestreo de aguas y precipitados salinos y su posterior análisis en laboratorio. Dichas metodologías se describen en el presente apartado.

\section{— Elaboración de mapas de sales}

La obtención de información sobre superficies extensas necesita la definición previa de una malla de puntos sobre los cuales se realizarán mediciones de los parámetros de interés. La metodología aquí aplicada se basa en la medición de la conductividad sobre apósitos impregnados de gel celulósico (hidroxipropilcelulosa), que fueron colocados sobre cada uno de los puntos de la red de adquisición de datos, midiéndose sobre ellos mediante un conductivímetro marca Crison, que incorpora una sonda especialmente adaptada para mediciones directas sobre paramentos (Gisbert et al. 2008).

Esta metodología permite obtener el valor de conductividad eléctrica obtenido tras la interacción entre el gel celulósico y las sales presentes en la superficie estudiada. La medida de la conductividad se ha comprobado como una aproximación suficientemente precisa para la determinación de las áreas de concentración salina en paramentos (Egartner y Sass 2016), además de ser sencilla, barata, rápida y de carácter no destructivo. Los resultados permiten conocer la distribución relativa de la acumulación de sales de forma cuantificada y, lo más importante para nuestro interés, la localización de los máximos salinos y su relación con patologías observables.

\section{- Toma de muestras}

Para conseguir conocer la naturaleza química y mineralógica del problema, se ha procedido a la toma de muestras según tres criterios principales:

- Puntos donde se observaron acumulaciones superficiales de sales, normalmente con aspecto pulverulento y de color blanquecino, que permitieron recoger material sólido.

- Zonas donde se localizaron los máximos en la cartografía de sales, permitieron obtener lixiviados puntuales mediante la aplicación de apósitos de celulosa (discos de 9x9 cm de lado, y $3 \mathrm{~mm}$ de espesor, de Arbocel BC 1000 impregnado en agua destilada), que se mantuvieron en contacto con el paramento durante 8 minutos $y$, tras su retirada, se diluyeron en $100 \mathrm{ml}$ de agua destilada para recuperar las sales así extraídas de la zona superficial. Esta metodología permite identificar problemas de acumulación de sales ya en sus fases tempranas, dado que la aplicación de los apósitos húmedos provoca un flujo de agua que va hacia el interior del paramento y retorna al apósito, movilizando las sales existentes tanto en la superficie como en la zona subsuperficial y ayudando así a la detección del problema antes de comenzar sus manifestaciones superficiales (Egartner y Sass 2016).

-Se recogió una muestra de agua superficial acumulada en un área de la cubierta que estaba en contacto con acumulaciones sólidas de deyecciones de palomas, de las cuales se recogió también una muestra sólida con 
el objetivo de realizar sobre ella un lixiviado con agua en laboratorio y analizar, de este modo, la contribución química de estos materiales al proceso estudiado.

\section{- Análisis de las muestras}

Las muestras recogidas se analizaron para conocer su composición desde distintas aproximaciones experimentales. Así, la muestra sólida salina se sometió a análisis mineralógico mediante difractometría de rayos $\mathrm{X}$, obteniéndose una determinación semicuantitativa de la presencia y abundancia relativa de los principales minerales. Se empleó un difractómetro de rayos $\mathrm{X}$ de polvo de ánodo rotatorio de $18 \mathrm{~kW}(60 \mathrm{kV}, 300 \mathrm{~mA})$, modelo RIGAKU D/max 2500, perteneciente al Servicio de Difracción de Rayos X y Análisis por Fluorescencia de la Universidad de Zaragoza, y la identificación de las fases minerales se ha realizó mediante la base de datos ICDD-Powder Difraction File2000.

Sobre las muestras líquidas obtenidas (el agua recogida en la zona de cubiertas, los lixiviados de los apósitos de celulosa aplicados sobre los paramentos y el lixiviado en laboratorio de las deyecciones sólidas de aves recogidas en la cubierta) se analizó la concentración de los principales aniones y cationes disueltos. Dichas muestras, una vez recogidas y adecuadamente estabilizadas, se enviaron al Centro de Análisis de Aguas, S.A. (CAASA) de Murcia, laboratorio acreditado por ENAC, donde se realizaron las determinaciones de conductividad y $\mathrm{pH}$ (ambos por electrometría) y del contenido en sulfato, cloruro, nitrato, nitrito (todos ellos por cromatografía iónica), bicarbonato (por acidimetría), amonio (por espectrometría de absorción molecular), sodio, potasio, calcio, magnesio, hierro y manganeso (mediante espectrometría de absorción atómica), empleando los métodos correspondientes según la normativa vigente en España.

En cuanto a los lixiviados de los apósitos de celulosa, se tuvo en cuenta el posible aporte químico procedente de los propios apósitos, analizando uno de dichos discos en condiciones de "blanco" experimental, es decir, sometiendo a análisis químico el lixiviado de un apósito que no había estado en contacto con el paramento. De este modo, los valores obtenidos en el análisis del "blanco" se han descontado de los correspondientes a los apósitos aplicados al monumento, para así obtener los valores relativos exclusivamente a la carga salina extraída de los paramentos.

\section{Resultados}

El análisis del presente estudio se centra en la investigación aplicada sobre la portada de la fachada oeste del monumento [figura 1]. Los procesos de deterioro identificados en su zona inferior corresponden, principalmente, a una arenización del material constructivo, intensa y ampliamente desarrollada, que da lugar incluso

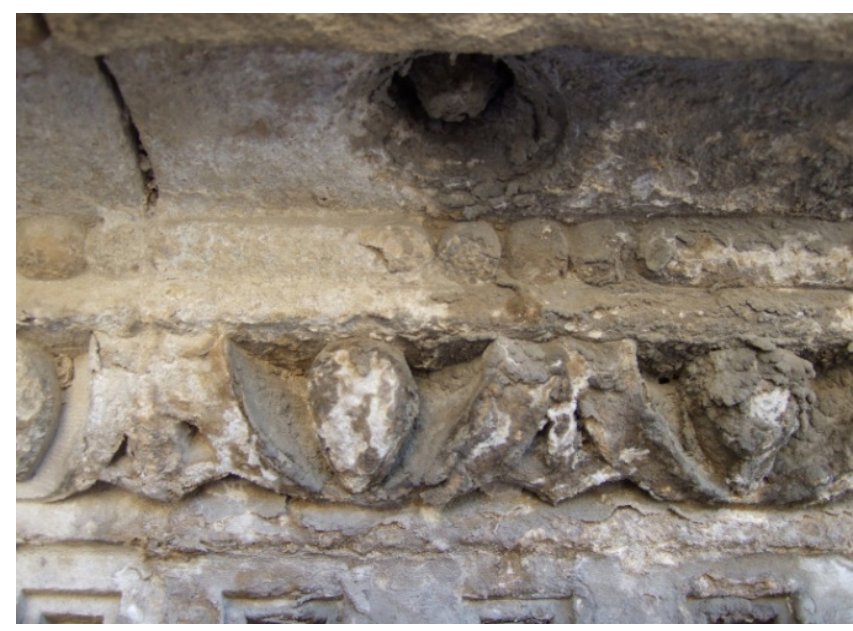

Figura 2.- Ejemplo del deterioro por acumulación de sales, con pérdida de volumen de la zona de labra. El detalle corresponde a la localización de la muestra UNSM-1 en la figura 3.

a pérdida de volúmenes de roca en zonas de labra del cuerpo inferior del muro por la precipitación de sales en forma de subeflorescencias [figura 2]. También se observan acumulaciones puntuales dispersas de eflorescencias salinas a distintas alturas en dicho muro.

El mapa de sales realizado a partir de las medidas de conductividad eléctrica sobre los paramentos de la fachada permite apreciar la irregular distribución de concentraciones salinas [figura 3], y se obtuvo mediante la integración superficial de los datos obtenidos según una malla de 100 puntos distribuidos al tresbolillo, indicados en la figura como puntos de color rojo y con un espaciado que osciló entre $25 \mathrm{~cm}$ y 1 m, según zonas. La interpolación se realizó mediante krigeaje.

El máximo salino detectado en esta fachada se localiza a

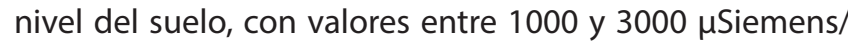
$\mathrm{cm}$ (en adelante, $\mu \mathrm{S} / \mathrm{cm}$ ). Se identifican además otras áreas donde la concentración salina es alta (valores de 500 a $1000 \mu \mathrm{S} / \mathrm{cm}$ ) tanto en zonas bajas cercanas al suelo como en otras localizaciones a mayor altura, aproximadamente a unos 6 metros desde el suelo. Se han localizado así cuatro grandes áreas de acumulación de cantidades apreciables de sales en los paramentos: El dintel de la puerta principal de la fachada, las zonas adyacentes a ambas jambas $y$, finalmente, la base de la torre norte. En todas ellas se han localizado amplias zonas con valores medidos de conductividad por encima de $500 \mu \mathrm{S} / \mathrm{cm}$, superándose en puntos concretos los $1000 \mu \mathrm{S} / \mathrm{cm}$. Estas áreas de concentración salina están relacionadas con la zona donde se observan las principales acumulaciones de deyecciones de palomas (dintel y torre N) y su lavado en la vertical hacia la parte baja del monumento. Destaca además la ausencia de un nivel más o menos continuo de acumulación de sales en la franja de ascenso capilar.

Se tomó una muestra de material sólido salino acumulado en forma de eflorescencia superficial (UNSM-1), y también 


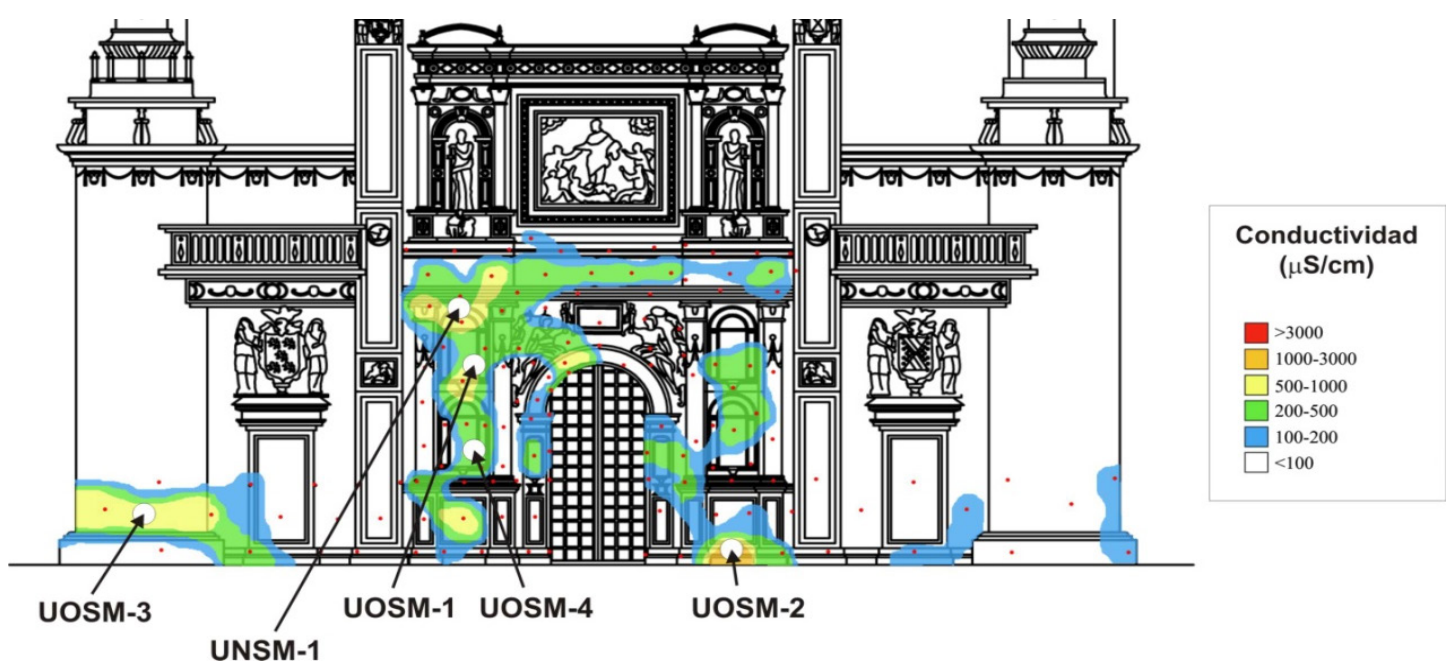

Figura 3.- Mapa elaborado a partir de los valores de conductividad obtenidos del análisis superficial de la zona inferior de la portada de la fachada oeste de El Salvador. Se indican además los puntos donde se recogieron muestras para su análisis, tanto de sales precipitadas (UNSM-1) como de apósitos de extracción de sales (UOSM-1 a UOSM-4).

\begin{tabular}{|c|c|c|c|c|c|c|c|}
\hline \multirow[b]{2}{*}{ Muestra } & \multirow{2}{*}{$\begin{array}{c}\begin{array}{c}\text { Lixiviado } \\
\text { deyecciones }\end{array} \\
\text { KK }\end{array}$} & \multirow{2}{*}{$\begin{array}{c}\begin{array}{c}\text { Agua de } \\
\text { cubiertas }\end{array} \\
\text { UAIE }\end{array}$} & \multicolumn{5}{|c|}{ Lixiviados de apósitos de extracción de sales } \\
\hline & & & UOSM-1 & UOSM-2 & UOSM-3 & UOSM4 & Blanco \\
\hline $\mathrm{pH}$ & 6,05 & 7,06 & - & - & - & - & - \\
\hline C.E. $(\mu \mathrm{S} / \mathrm{cm})$ & 1803 & 399 & 1295 & 1304 & 287 & 807 & 140 \\
\hline $\mathrm{Ca}(\mathrm{mg} / \mathrm{l})$ & 25,7 & 67,13 & 86,41 & 82,41 & 27,6 & 50,81 & 15,84 \\
\hline $\mathrm{Mg}(\mathrm{mg} / \mathrm{l})$ & 13,34 & 4,29 & 20,38 & 14,56 & 5,09 & 31,3 & 1,76 \\
\hline $\mathrm{Na}(\mathrm{mg} / \mathrm{l})$ & 12,61 & 5,17 & 94,03 & 124,32 & 21,05 & 58,79 & 12,45 \\
\hline $\mathrm{K}(\mathrm{mg} / \mathrm{l})$ & 469,13 & 15,62 & 79,94 & 66,9 & 5,93 & 21,54 & 1,24 \\
\hline $\mathrm{HCO}_{3}(\mathrm{mg} / \mathrm{l})$ & 861,26 & 107,06 & 84,46 & 28,55 & 35,69 & 32,12 & 42,03 \\
\hline $\mathrm{SO}_{4}(\mathrm{mg} / \mathrm{l})$ & 51,64 & 53,51 & 12,52 & 21,22 & 27,16 & 48,16 & 8,39 \\
\hline $\mathrm{Cl}(\mathrm{mg} / \mathrm{l})$ & 53,98 & 12,22 & 101,81 & 168,36 & 25,41 & 37,71 & 13,59 \\
\hline $\mathrm{NO}_{3}(\mathrm{mg} / \mathrm{l})$ & $<1$ & 61,08 & 395,83 & 391,13 & 54,53 & 304,34 & 0,58 \\
\hline $\mathrm{NO}_{2}(\mathrm{mg} / \mathrm{l})$ & $<0,1$ & 0,51 & $<0,1$ & $<0,1$ & $<0,1$ & $<0,1$ & $<0,1$ \\
\hline $\mathrm{NH}_{4}(\mathrm{mg} / \mathrm{l})$ & 77,53 & 0,74 & $<0,04$ & $<0,04$ & $<0,04$ & $<0,04$ & $<0,04$ \\
\hline $\mathrm{Fe}(\mathrm{mg} / \mathrm{l})$ & 1,12 & $<0,05$ & $<0,05$ & $<0,05$ & $<0,05$ & $<0,05$ & $<0,05$ \\
\hline $\mathrm{Mn}(\mathrm{mg} / \mathrm{l})$ & 0,04 & $<0,02$ & 0,03 & $<0,02$ & $<0,02$ & $<0,02$ & $<0,02$ \\
\hline
\end{tabular}

Tabla 1.- Resultados del análisis químico de los lixiviados de los apósitos aplicados, del agua de cubiertas recogida y del lixiviado de deyecciones realizado en laboratorio. En los valores correspondientes a los lixiviados de los apósitos ya se ha descontado el correspondiente al blanco (explicación en el apartado de Metodología).

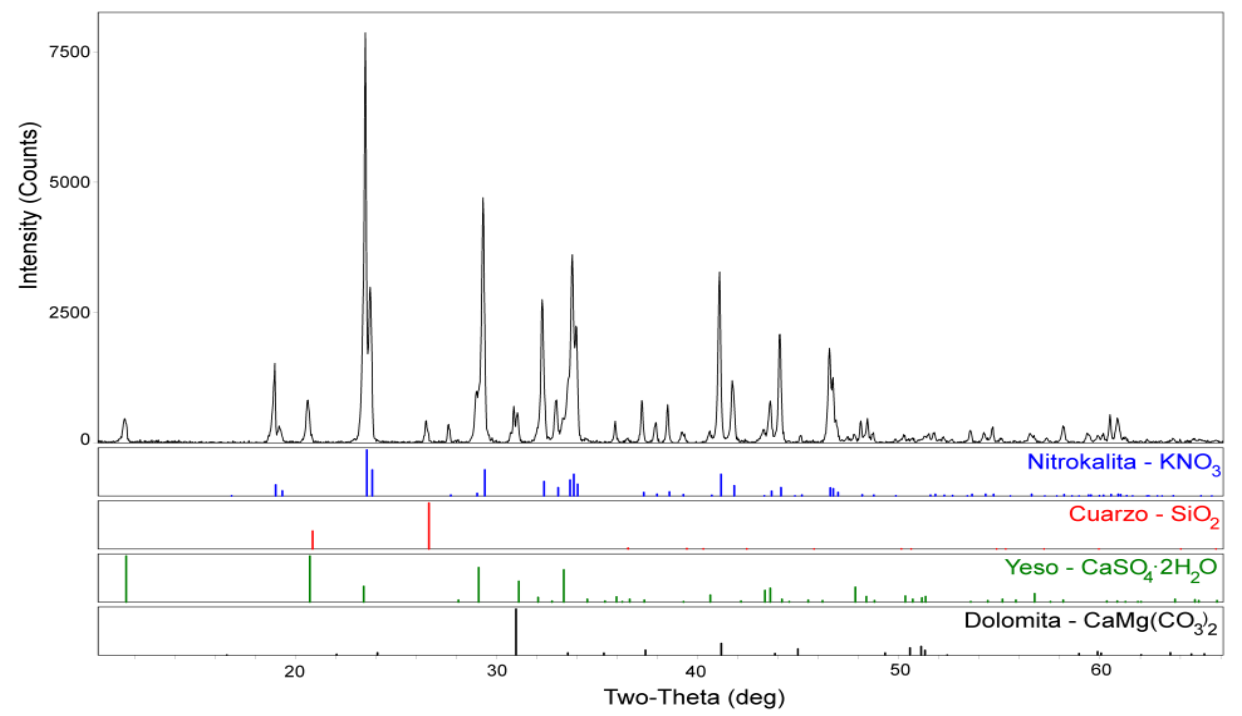

Figura 4.- Difractograma de la muestra de sales precipitadas UNSM-1 (se puede observar su aspecto superficial en la figura 2 y su localización en la figura 3) 
se realizaron cuatro aplicaciones de apósitos de celulosa (UOSM-1 a UOSM-4), coincidiendo con las áreas de máximos medidos de conductividad en esta fachada [figura 3].

Los resultados del análisis químico de los lixiviados de los apósitos de celulosa se presentan en la tabla 1, junto con los de una muestra de agua recogida directamente en la zona de cubiertas del monumento, con ocasión de un periodo de lluvias. Igualmente, la tabla recoge los valores obtenidos en el análisis del lixiviado en laboratorio de las deyecciones de aves recogidas en la zona de cubiertas. Para dicho lixiviado se tomaron 5,2 gr de deyecciones sólidas y se pusieron en contacto con $100 \mathrm{ml}$ de agua destilada, en condiciones de laboratorio $\left(25^{\circ} \mathrm{C}\right)$ y bajo agitación continua. Pasadas 2 horas, se dejó decantar y se filtró, procediéndose al análisis del lixiviado. Teniendo en cuenta la cantidad de material sólido de partida, la concentración del lixiviado obtenido y su volumen, se ha calculado que la fracción salina solubilizada corresponde al 3,4\% del peso total de la muestra sólida sometida a ensayo.

El análisis mineralógico realizado sobre la muestra de sales precipitadas UNSM-1 ha permitido obtener el difractograma de la figura 4. Dicha determinación, de carácter semicuantitativo, permitió comprobar que la muestra estaba constituida mayoritariamente por $\mathrm{KNO}_{3}$ (nitrato potásico, bajo la forma mineral denominada nitrokalita o nitro), con contenidos significativamente menores en $\mathrm{CaSO}_{4} \cdot 2 \mathrm{H}_{2} \mathrm{O}$ (yeso), $\mathrm{SiO}_{2}$ (cuarzo) y $\mathrm{CaMg}\left(\mathrm{CO}_{3}\right)_{2}$ (dolomita).

Los resultados del análisis químico indican que las muestras USOM-1 y UOSM-2 presentan el mayor contenido salino total, tal y como reflejan tanto el valor de conductividad eléctrica medido en la disolución como los valores de concentración de los diferentes iones analizados.

La muestra UOSM-1 procede del análisis de un apósito aplicado en una zona próxima a una de las más afectadas visualmente [figura 2], donde además había una concentración salina visible y que, tras su recogida y análisis mediante difractometría de rayos $\mathrm{X}$, permitió conocer que dichas sales eran principalmente nitrato potásico (nitrokalita) y yeso, acompañadas por cantidades muy bajas pero detectables de cuarzo y dolomita, seguramente procedentes del paramento rocoso. Por su parte, el análisis químico del lixiviado del apósito refleja altos contenidos en $\mathrm{NO}_{3}^{-}, \mathrm{Cl}^{-}, \mathrm{Na}^{+}$y K${ }^{+}$, además de proporciones relativamente altas de $\mathrm{Ca}^{2+} \mathrm{y} \mathrm{HCO}_{3}$. Dicho lixiviado es compatible con la presencia de nitrokalita y halita como minerales salinos principales, acompañados por yeso y calcita.

Los resultados analíticos de los otros apósitos muestran similitudes composicionales con la muestra UOSM-1 aunque en concentraciones totales proporcionales a su contenido salino total.

\section{Discusión}

Las patologías observadas en la fachada de la iglesia de El Salvador guardan una clara relación con la acumulación de sales procedentes de las deyecciones de palomas que frecuentemente ocupan tanto la zona de cubiertas como los relieves que sobresalen de dicha fachada. La intensidad del deterioro es máxima en las zonas donde la acumulación de sales y humedades es más evidente, dando lugar a patologías que incluyen descamación, arenización, pérdida de material y desarrollo de pátinas y costras. Las humedades proceden mayoritariamente del salpiqueo del agua de cubiertas y del impacto directo del agua de lluvia sobre los muros, así como del ascenso capilar del agua de escorrentía en los episodios de lluvia o en las operaciones de limpieza urbana. El posible aporte por ascenso capilar desde el nivel freático no se considera importante, ya que éste se localiza a una profundidad media de $4 \mathrm{~m}$ en la zona del monumento (Equipo Arbotante 2009).

La identificación de las patologías más graves resulta evidente, ya que conllevan procesos de deterioro claramente visibles y acompañados por la acumulación de sales (que con su color blanco destaca cromáticamente), pero el mapa de conductividad superficial ha permitido comprobar que las acumulaciones salinas se extienden cubriendo superficies mucho más amplias que las zonas afectadas visualmente identificables [figura 3]. Estas áreas ampliadas corresponden a zonas donde se están acumulando las sales y que, tarde o temprano, provocarán patologías graves como las ya identificadas, por lo que resulta importante su localización y tratamiento antes de alcanzarse dicha fase avanzada de deterioro.

Los valores analíticos obtenidos ofrecen información valiosa, pero a la hora de analizar de forma comparativa los resultados de los lixiviados de los apósitos es más adecuado emplear diagramas que muestren las relaciones iónicas entre los principales elementos de interés, tal y como es habitual en disciplinas geoquímicas, ya que permiten apreciar similitudes composicionales en condiciones de concentración total muy diferentes. En la figura 5 se han

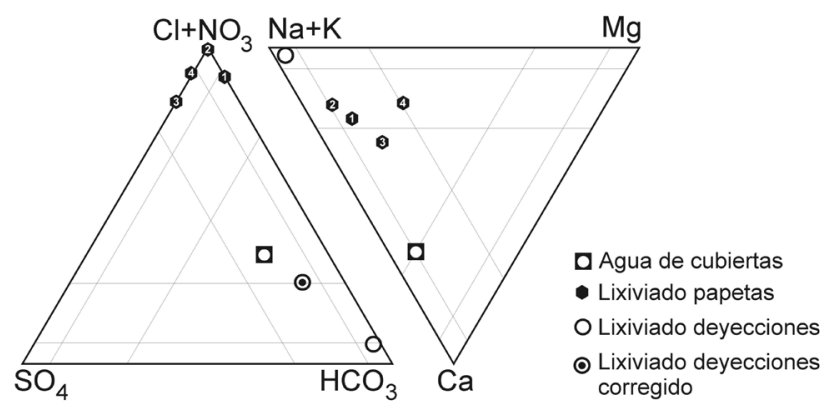

Figura 5.- Proyección de los resultados del análisis químico realizado en laboratorio sobre muestras de apósitos, aguas de cubierta y lixiviado de deyecciones. Los puntos representan las proporciones iónicas en miliequivalentes/l. El lixiviado corregido se ha calculado suponiendo todo el $\mathrm{NH}_{4}{ }^{+}$bajo la forma $\mathrm{NO}_{3}{ }^{-}$. 
proyectado los puntos correspondientes a los apósitos, según las proporciones iónicas de los principales cationes y aniones, expresados en miliequivalentes por litro (meq/l), y una vez descontados los valores del blanco.

Este diagrama se ha modificado a partir de los diagramas triangulares de Eugster y Hardie (1978), con el objetivo de incluir el ion $\mathrm{NO}_{3}$, cuya presencia es muy reducida en la naturaleza pero que aquí se erige en el constituyente disuelto más abundante; dicho ion se ha colocado en el vértice superior del triángulo aniónico, por afinidad con el $\mathrm{Cl}^{-}$en los procesos de concentración por lavado de sales y evaporación. Se observa que las cuatro muestras de apósitos aparecen agrupadas en ambos diagramas; en el aniónico, en torno al vértice correspondiente a $\left(\mathrm{Cl}^{-}\right.$ $\left.+\mathrm{NO}_{3}{ }^{-}\right)$, y en el catiónico, en un área interna del triángulo pero claramente más cerca del vértice $\left(\mathrm{Na}^{+}+\mathrm{K}^{+}\right)$. Estas agrupaciones geoquímicas reflejan que, a pesar de que los apósitos proceden de diferentes zonas de la fachada del monumento y reflejan concentraciones totales variables, los procesos involucrados en la acumulación de sales son comunes en todas ellas, por lo que pueden ser explicados por un mecanismo común, independientemente de la concentración salina total que muestre cada zona.

El empleo de las unidades de concentración en meq/l y su proyección sobre diagramas de proporciones iónicas nos permite valorar de forma conjunta los resultados de los apósitos y los procedentes del análisis del agua recogida en el monumento en la zona de cubiertas. Esta muestra líquida se tomó en ocasión de un periodo de lluvia, y su carga química disuelta es representativa de la interacción entre el agua de lluvia y los materiales sólidos existentes en la zona de cubiertas (rocas, morteros, deyecciones de aves y partículas atmosféricas allí depositadas, principalmente). Su concentración total es relativamente baja, como indica el valor de conductividad eléctrica medido (aproximadamente $400 \mu \mathrm{S} / \mathrm{cm}$ ). La composición química del agua de cubiertas está dominada por los aniones $\mathrm{HCO}_{3}^{-}$y $\mathrm{NO}_{3}^{-}$y por el catión $\mathrm{Ca}^{2+} \mathrm{y}$, en menor medida, $\mathrm{K}^{+}$, y su posición en el diagrama de proporciones iónicas indica que se trata de una solución principalmente bicarbonatada-cálcica, claramente alejada de los puntos correspondientes a los apósitos, sobre todo en el caso de los aniones. El $\mathrm{Ca}^{2+}$ disuelto en el agua de cubiertas procede principalmente de la disolución que tiene lugar en su interacción con la fracción carbonatada del sustrato rocoso, debido a su carácter marcadamente ácido por efecto del lixiviado in situ de las deyecciones de palomas, mientras que el $\mathrm{K}^{+}$proviene casi en exclusiva de dicho lixiviado.

También se ha representado en la figura 5 la muestra relativa al lixiviado con agua destilada de las deyecciones sólidas, el cual presenta un $\mathrm{pH}$ ligeramente ácido $(\mathrm{pH}=6,05)$, un valor de conductividad eléctrica muy elevado (C.E. $=1803 \mu \mathrm{S}$ / $\mathrm{cm}$ ) y una composición química dominada por la presencia

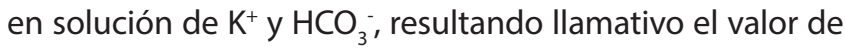
concentración relativamente elevado de $\mathrm{NH}_{4}^{+}$, así como una ausencia de $\mathrm{NO}_{3}^{-}$prácticamente total. La representación de los resultados de esta muestra sobre los diagramas de proporciones iónicas de la figura 5 permite apreciar que se trata de una solución bicarbonatada potásica, con una proporción en solución muy inferior para el resto de iones analizados. El bicarbonato procede sin duda de los derivados del ácido úrico presentes en las deyecciones de las palomas, y es el anión disuelto proporcionalmente más importante en el lixiviado.

\section{—Origen y evolución de las especies de nitrógeno}

La relación entre las acumulaciones de deyecciones de aves y las áreas afectadas por acumulación de sales en la fachada estudiada parece evidente a partir de la figura 3, pero la composición química del lixiviado realizado en laboratorio y de las aguas de cubiertas ofrece, al menos a priori, algunas diferencias que es necesario explicar. En primer lugar, el lixiviado prácticamente no presenta iones $\mathrm{NO}_{3}^{-}$en disolución, encontrándose todo el nitrógeno disuelto en la forma $\mathrm{NH}_{4}^{+}$. Por otra parte, el agua de cubiertas presenta abundante $\mathrm{NO}_{3}^{-}$en disolución, pero el nitrógeno también aparece formando parte de las especies químicas $\mathrm{NH}_{4}^{+} \mathrm{y}$ $\mathrm{NO}_{2}$. Finalmente, los apósitos contienen abundante $\mathrm{NO}_{3}^{-}$no presentan concentraciones medibles apreciables ni de $\mathrm{NH}_{4}{ }^{+}$ni de $\mathrm{NO}_{2}{ }^{-}$, mientras que la muestra de sal precipitada y analizada por DRX posee abundante $\mathrm{KNO}_{3^{\prime}}$ es decir, el nitrógeno ha precipitado bajo la forma aniónica $\mathrm{NO}_{3}$.

Este hecho es fácilmente interpretable a la luz de las características propias del ciclo del nitrógeno, cuyo punto de partida lo constituye su acumulación en las deyecciones de las aves. El metabolismo de estos organismos superiores genera unos desechos ricos en $\mathrm{N}$ en forma amoniacal $\left(\mathrm{NH}_{4}^{+}\right)$, que mediante procesos estrictamente bacterianos pasan primero a formas nitrosas (nitrosación, pasando el $\mathrm{N}$ a la especie $\mathrm{NO}_{2}^{-}$) y luego a formas nítricas (nitratación, pasando a la especie $\mathrm{NO}_{3}^{-}$). Este proceso avanza desde formas amoniacales hacia formas con un grado de oxidación progresivamente mayor, en función de la energía que obtienen las bacterias en el proceso de oxidación de las diferentes formas del nitrógeno. Así, por ejemplo, la proporción de nitratos presenta una tendencia estacional debido a las condiciones que regulan la actividad microbiana, siendo estas especies oxidadas más abundantes cuando la temperatura ambiental aumenta (Johnson et al. 1986).

Un aspecto importante en relación con los procesos de nitrosación y nitratación es que la energía que obtienen las bacterias en el primero de ellos (paso de formas amoniacales a nitrosas) es muy baja, por lo que su transición es muy rápida y así las formas $\mathrm{NO}_{2}$ - desaparecen muy rápidamente del medio, siendo usual encontrar proporciones cuantitativamente dominantes de $\mathrm{NH}_{4}^{+}$(aún no oxidado) y de $\mathrm{NO}_{3}^{-}$(producto oxidado final), lo que explica que en el lixiviado de las deyecciones sólo se encontrara $\mathrm{N}$ en forma amoniacal $\left(\mathrm{NH}_{4}^{+}\right)$. También explica que la muestra de agua de cubiertas presentase un contenido predominante de 
formas nítricas $\left(\mathrm{NO}_{3}{ }^{-}\right)$, pero con presencia detectable de $\mathrm{NH}_{4}^{+}$y de $\mathrm{NO}_{2}^{-}$, ya que el lixiviado natural que provoca el agua de lluvia moviliza el contenido soluble de las deyecciones acumuladas y la actividad bacteriana tiende a hacer predominantes las formas nítricas. El nitrógeno presente en las sales precipitadas en los paramentos aparece exclusivamente bajo formas nítricas, ya que se trata del punto final del trayecto que experimentan estos solutos.

En el triángulo aniónico de la figura 5 se ha proyectado el punto teórico calculado para el lixiviado de las deyecciones, suponiendo que todo el $\mathrm{N}$ determinado químicamente se hubiese encontrado en forma nítrica, y no en forma amoniacal como realmente indicó el análisis realizado. El punto teórico así calculado se desplaza desde su ubicación original, prácticamente en el vértice correspondiente al $\mathrm{HCO}_{3}$, , hasta situarse muy próximo al que corresponde al agua de cubiertas, lo que permite concluir que la carga química aniónica del agua de cubiertas en este monumento procede del lixiviado natural a partir de las deyecciones de aves acumuladas, con la única particularidad de que la especie química bajo la cual se presenta el $\mathrm{N}$ dependerá de la intensidad de la actividad bacteriana y del mayor o menor grado de limpieza y mantenimiento del monumento, ya que las deyecciones recientes presentan una proporción mayoritaria de $\mathrm{NH}_{4}^{+}$, que va disminuyendo con el tiempo en favor del $\mathrm{NO}_{3}$ :

En relación con la evolución de las especies químicas del nitrógeno en este tipo de procesos, cabe referir aquí los resultados presentados en el interesante artículo de Gómez-Heras et al. (2004), donde procedieron a realizar un lixiviado a partir de deyecciones de palomas que sometieron después a evaporación en laboratorio para determinar la mineralogía de las sales precipitadas, donde encontraron elevadas concentraciones de $\mathrm{K}^{+}, \mathrm{Na}^{+}, \mathrm{Cl}^{-}, \mathrm{HCO}_{3}^{-}$ y $\mathrm{SO}_{4}{ }^{2-}$, pero una proporción más baja de $\mathrm{NO}_{3}{ }^{-}$respecto del que esperaban obtener, teniendo en cuenta la abundancia de nitratos entre las sales participantes en este tipo de deterioros. A la vista de los resultados analíticos que presentan, no se puede saber si determinaron el contenido en $\mathrm{NH}_{4}{ }^{+}$, que seguramente debió ser la especie química bajo la cual se encontraba el $\mathrm{N}$ movilizado al realizar la extracción mediante agua destilada.

\section{-Interpretación geoquímica}

La interpretación química de la proyección de los resultados relativos a los cationes (figura 5, triángulo derecho) no permite una definición simple del proceso. Así, mientras que el lixiviado de laboratorio presenta una composición dominada por los elementos alcalinos (sobre todo $\mathrm{K}^{+}$) respecto del resto de cationes presentes, en el agua de cubiertas predomina claramente el $\mathrm{Ca}_{2}{ }^{+}$. El lixiviado en laboratorio indica que las deyecciones son la fuente principal del $\mathrm{K}^{+}$movilizado. Por otra parte, el análisis del agua de cubiertas indica que, cuando tienen lugar los episodios de lluvia, el agua no sólo moviliza la carga química presente en las deyecciones, sino que también es capaz de solubilizar otros elementos susceptibles de reaccionar rápidamente y que están presentes en los materiales constructivos del monumento: rocas de tipo arenisca calcárea y morteros de cal y de yeso. De todos ellos, los constituyentes más susceptibles de reaccionar rápidamente al contacto con el agua de lluvia son el yeso y la calcita presentes en rocas y morteros, por lo que por este proceso se solubilizarán preferentemente $\mathrm{Ca}^{2+}, \mathrm{HCO}_{3}^{-} \mathrm{y}$ $\mathrm{SO}_{4}{ }^{2-}$, lo que provoca que las aguas de cubiertas incorporen elevadas concentraciones de $\mathrm{Ca}^{2+}$ en disolución.

La solubilización de cationes mediante lixiviado con agua destilada a partir de rocas como las aquí empleadas como materiales constructivos ha sido estudiada, por ejemplo, por Buj Fandos et al. (2010). En dicho trabajo se comprueba que, para el caso de una litoarenita similar mineralógicamente a las de la fachada de Iglesia de San Salvador de Úbeda, el principal catión solubilizado era el $\mathrm{Ca}^{2+}$ (aproximadamente el $50 \%$ del total de cationes disueltos), seguido por $\mathrm{Na}^{+}$(en torno al 30\%) y $\mathrm{K}^{+}$(alrededor del 18\%), y finalmente $\mathrm{Mg}^{2+}$ (5\%).

De todo ello se deduce que el agua de lluvia entra en contacto con las deyecciones acumuladas, solubiliza los elementos movilizables descendiendo su $\mathrm{pH}$ y, simultáneamente, provoca el lixiviado parcial de los cationes y aniones más solubles de rocas y morteros. Ello explica que las aguas de cubiertas lleguen a enriquecerse en $\mathrm{Ca}^{2+}$ por encima de lo que sería esperable únicamente a partir de la aportación química de las deyecciones, y de ahí la diferencia observada al proyectar los puntos sobre los diagramas de proporciones catiónicas de la figura 5 .

\section{— Recomendaciones de actuación}

El interés de este tipo de investigaciones es servir como guía de las actuaciones de mantenimiento y/o restauración a llevar a cabo en un monumento o edificio civil afectados por deterioros de esta naturaleza.

En el caso de la iglesia de San Salvador de Úbeda, las recomendaciones emanadas de este estudio se dirigieron hacia tres tipos de actuaciones para minimizar los efectos de la acumulación de sales, independientemente de las actuaciones necesarias propias para la recuperación de los elementos artísticos afectados por patologías observables.

En primer lugar, la eliminación de la mayor cantidad posible de acumulaciones salinas en los paramentos, mediante metodologías de desalación superficial. El mapa de sales indicó las zonas donde aplicar la desalación y con qué intensidad, en función de los rangos de acumulación observados.

En segundo lugar, la ubicación de elementos de evacuación de aguas pluviales, ya que se ha comprobado que la 
redistribución de material salino se produce en disolución, en sentido descendente desde los puntos de acumulación de deyecciones (área de cubiertas y relieves salientes de la fachada y la torre).

En tercer lugar, la limpieza periódica de las acumulaciones de deyecciones de aves, incluyendo dispositivos de control de las palomas (por ejemplo, mediante mecanismos ahuyentadores de aves) en las zonas más sensibles por su valor artístico, y el mantenimiento de los elementos de evacuación de aguas pluviales, que garantice su correcta funcionalidad.

\section{Conclusiones}

En el desarrollo de patologías por acumulación de sales en el patrimonio construido participan los elementos químicos solubles y movilizados por el agua que circula sobre y a través de los paramentos. Uno de las fuentes más importantes de solutos es la acumulación de deyecciones de aves, identificada como tal en diferentes estudios e informes técnicos, pero que necesitaba estudios metodológicos que informasen acerca de cómo se produce dicho aporte químico. En el presente trabajo se seleccionó un caso donde el deterioro debía su origen mayoritariamente a los solutos aportados por el lavado de deyecciones de aves por el agua de lluvia, en concreto la fachada de la iglesia de San Salvador de Úbeda.

Los resultados obtenidos han permitido comprobar que las deyecciones de aves (en este caso concreto, palomas) contienen una elevada carga movilizable por contacto con aguas de lluvia, destacándose la abundancia de potasio y de nitrógeno, elementos que normalmente se deberían presentar en bajas concentraciones en disolución. La especie química bajo la que se presenta el nitrógeno en estas aguas puede variar en función de la estación del año, de la cantidad de deyecciones y del tiempo que lleven acumuladas, de manera que las de deposición reciente tienden a liberar el nitrógeno en forma amoniacal $\left(\mathrm{NH}_{4}^{+}\right)$, mientras que las más antiguas o las lixiviadas en periodos cálidos lo hacen en forma nítrica $\left(\mathrm{NO}_{3}{ }^{-}\right)$, debido a las diferencias en la intensidad de la actividad bacteriana previa.

La inspección visual posibilita localizar acumulaciones superficiales de sales, debido a su coloración blanquecina, pero los mapas de conductividad han permitido delimitar las zonas donde se estaban acumulando dichas sales pero aún no se visualizaban los deterioros. La extracción mediante apósitos de las sales presentes en los puntos con valores máximos de conductividad ha permitido relacionar el origen de estos solutos con el lixiviado por el agua de lluvia de las deyecciones acumuladas en cubiertas y salientes de la fachada. El razonamiento geoquímico que ha permitido llegar a esta conclusión se ha basado fundamentalmente en el análisis de la cantidad y proporción relativa de aniones, ya que los cationes se muestran más susceptibles a incorporar la participación de otras fuentes potenciales de solutos (como, en este caso, los propios materiales constructivos como rocas y morteros de cal y de yeso).

Las áreas afectadas con mayor intensidad presentan eflorescencias superficiales de sales precipitadas, mayoritariamente constituidas por $\mathrm{KNO}_{3}$. Las zonas que los mapas de conductividad delimitan como afectadas por acumulación de sales en una fase incipiente presentan un contenido en sales donde predominan los cationes alcalinos $\mathrm{Na}^{+}$y K${ }^{+}$y los aniones monovalentes $\mathrm{Cl}^{-}$y $\mathrm{NO}_{3}$. En esta fase incipiente, las sales se acumulan mayoritariamente como subeflorescencias, pero la aplicación de apósitos de celulosa y su posterior análisis químico permite identificar la composición química de dichas sales, posibilitando así detectar el problema en una fase precoz, anterior a que se manifiesten patologías que puedan afectar al material constructivo.

Como conclusión metodológica de este trabajo, se considera que la combinación de la realización de los mapas de conductividad junto con la extracción de apósitos en los puntos de valores máximos, además del muestreo de aguas que pueden afectar al edificio (aguas de cubiertas o subterráneas, por ejemplo) y su análisis e interpretación geoquímica, constituyen la mejor y más completa aproximación para identificar la procedencia de los solutos que se movilizan y acumulan en un caso concreto. De ello se podrán derivar las recomendaciones de actuación para llevar a cabo la limpieza y el plan de mantenimiento adecuado, evitando la progresión del proceso por repetición del mecanismo de acumulación de sales.

\section{Agradecimientos}

Agradecemos a la Diputación de Jaén y al Instituto Geológico y Minero de España por su autorización para usar los datos de los informes realizados sobre el edificio. También queremos expresar nuestro agradecimiento a D. Enrique F. Oliver Pina, Técnico del Laboratorio de Geoquímica del Departamento de Ciencias de la Tierra de la Universidad de Zaragoza, por su apoyo a la hora de diseñar y ejecutar la metodología química del presente trabajo. Igualmente queremos expresar nuestro agradecimiento a las recomendaciones de dos revisores anónimos, que han contribuido a mejorar la calidad del presente trabajo

\section{Bibliografía}

BLANCO, M., BUJ, O., COLUCCI, F. et al. (2010):“Estudio y cartografia de sales en paramentos pétreos: innovaciones tecnológicas con este propósito". La Ciencia y El Arte, 2: 162-170.

BUJ FANDOS, O., LÓPEZ JULIÁN, P. L., GISBERT AGUILAR, J. (2010): “Caracterización petrofísica y geoquímica de varias rocas turolenses de usos constructivos para la obtención de índices de calidad". Teruel, 93: 153-180. 
DYER, T. (2017): "Deterioration of stone and concrete exposed to bird excreta - Examination of the role of glyoxylic acid". International Biodeterioration \& Biodegradation, 125: 125:141.

EGARTNER, I. \& SASS, O. (2016): “Using paper pulp poultices in the field and laboratory to analyse salt distribution in building limestones". Heritage Science, 4:41.

EQUIPO ARBOTANTE (2009): “Estudio del material pétreo y sus productos de alteración de la iglesia de El Salvador de Úbeda (Jaén)". Informe y Anexos (inédito). Diputación Provincial de Jaén.

EUGSTER, H. \& HARDIE, L. (1978): “Saline Lakes". En: Lerman, A. (Ed.): Lakes: Chemistry, Geology, Physics. New York. Springer Verlag.

FLATT, R.J. (2002): "Salt damage in porous materials: how high supersaturations are generated". Journal of Crystal Growth, 242: 435-454.

GARABITO, J., MANSO, J.M., RODRÍGUEZ, A.et al. (2013): “Métodos para la limpieza física, química y biológica de las fábricas de piedra de monumentos históricas. El caso de San Lorenzo del Real de Burgos". Informes de la Construcción, 65: 367-380.

GISBERT, J., NAVARRO, P., FRANCO, B. et al. (2008): "Patologías en paramentos pétreos: Metodologías de estudio, diagnóstico, previsión en la evolución y desalación". En IX Congreso Internacional (CICOP) de Rehabilitación del Patrimonio Arquitectónico y Edificación. Sevilla (España).

GIUSTETTO, R., MOSCHELLA, E.M., CRISTELLOTTI, M. \& COSTA, E. (2017) "Deterioration of building materials and artworks in the 'Santa Maria della Stella' church, Saluzzo (Italy): Causes of decay and possible remedies". Studies in Conservation, 62: 474-493.

GÓMEZ-HERAS, M., BENAVENTE, D., ÁLVAREZ DE BUERGO, M. \& FORT, R. (2004): "Soluble salt minerals from pigeon droppings as potential contributors to the decay of stone based Cultural Heritage". European Journal of Mineralogy., 16: 505-509.

GROSSI, C.M. y ESBERT, R.M. (1994): "Las sales solubles en el deterioro de rocas monumentales. Revisión bibliográfica". Materiales de Construcción, 44: 15-30.

JOHNSON, D.W., COLE, D.W., VAN MIERGROET, H. \& HORNG, F.W. (1986): "Factors affecting anion movement and retention in four forest soil". Soil Science Society of America Journal, 50: 776-783.

LÓPEZ-ACEVEDO, V., VIEDMA, C., GONZALEZ, V. \& LA IGLESIA, A. (2007): "Salt crystallization in porous construction materials II. Mass transport and crystallization processes". Journal of Crystal Growth, 182: 103-110.

SCHAFFER, R.J. (1932): The weathering of natural building stones. John Wiley \& Sons, Londres. 149 págs.

SPENNEMANN, D.H., PIKE, M. \& WATSON, M.J. (2017): “Behaviour of Pigeon Excreta on Masonry Surfaces". Restoration of Buildings and Monuments, 23: 15-28.
WINKLER, E.M. (1973): Stone: Properties, Durability in Man's Environment. Springer Verlag, New York. 230 págs.

ZUFFA, G.G. (1980): "Hybrid arenites: their composition and classification". Journal of Sedimentary Petrology, 50: 21-29.

\section{Autor/es}

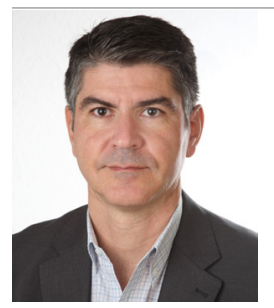

\section{Pedro Luis López Julián}

pllopez@unizar.es

Escuela Universitaria Politécnica de La Almunia. Zaragoza

Doctor en Ciencias Geológicas por la Universidad de Zaragoza (2004), ha extendido su campo de especialización doctoral al ámbito aplicado de la geoquímica de los procesos de alteración de materiales constructivos. Fue profesor en el Departamento de Ciencias de la Tierra de la Universidad de Zaragoza (2001-2008), adscrito al Área de Petrología y Geoquímica, y actualmente es profesor en la Escuela Universitaria Politécnica de La Almunia, responsable de asignaturas relacionadas con la Geología y la Ingeniería Civil (Geotecnia, Ingeniería Geológica e Hidrología Subterránea). Es miembro del Grupo de Investigación de Ingeniería Hidráulica y Ambiental, reconocido por el Gobierno de Aragón, desde 2017, donde continúa su actividad investigadora previa como miembro del Grupo de Investigación Geotransfer, de la Universidad de Zaragoza (2005-2016). Desarrolla además actividad investigadora actual en líneas relacionadas con materiales constructivos y reciclaje de residuos de construcción y demolición, tanto en edificación como en geotecnia para obra civil.

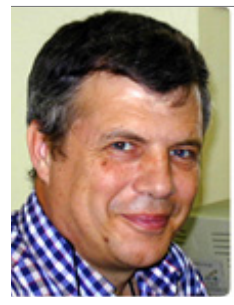

\author{
Josep Gisbert Aguilar \\ gisbert@unizar.es \\ Departamento de Ciencias de la Tierra de \\ la Universidad de Zaragoza
}

Doctor en Geología y profesor titular de Petrología en la Universidad de Zaragoza. Desde 1993 trabaja en caracterización, patologías y restauración de materiales pétreos (roca y morteros). Ha realizado más de 80 informes sobre restauraciones de edificios de patrimonio histórico artístico, trabajando con restauradores y otros profesionales de este campo. Ha asesorado restauraciones en edificios emblemáticos del patrimonio español como son el Pórtico de la Gloria de la Catedral de Santiago de Compostela, la Fachada de los Colegios Mayores de la Universidad de Salamanca o la Mezquita de Córdoba. Ha desarrollado varias aplicaciones prácticas en técnicas y métodos para la restauración de la piedra, destacando un sistema rápido y preciso para realizar mapas de sales superficiales en edificios y el sistema automático "Gunpoint mix" para producir papetas de celulosa. 


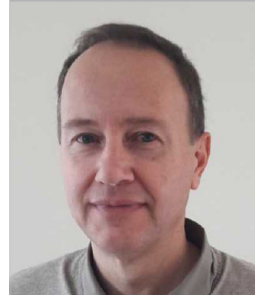

\section{José Ángel Pérez Benedicto \\ joanpebe@unizar.es}

Escuela Universitaria Politécnica de la Almunia. Zaragoza

Doctor por la Universidad Politécnica de Madrid, con el tema de su Tesis Doctoral "Estudio experimental sobre propiedades mecánicas del hormigón reciclado con áridos procedentes de la no calidad en prefabricación", es Máster en Técnicas y Sistemas de Edificación, Estudios Superiores de la Edificación, Ingeniero Civil, Graduado en Ingeniería de Edificación y Arquitecto Técnico. Lleva trabajando desde 2008 con la revalorización de residuos de hormigón. Desde 1999 es profesor titular en la Escuela Universitaria Politécnica de la Almunia, desempeñando durante los años 2009 a 2015 la Coordinación de Estudios de Arquitectura Técnica y de 2012 a 2016 la Subdirección de Investigación. Desde 2016 es miembro de la Comisión 4 Uso y Mantenimiento en ACHE. Con publicaciones en diversas revistas científicas y Codirector de 2 tesis doctorales sobre hormigones reciclados. Con despacho profesional desde 1986 y administrador de Pérez Benedicto Ingeniería S.L.

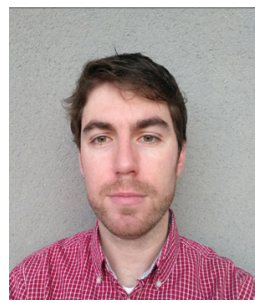

\section{Ángel Salesa Bordonaba}

asalebor@unizar.es

Escuela Universitaria Politécnica de la Almunia. Zaragoza

Es Doctor en Ingeniería de la Construcción e Ingeniero de Caminos, Canales y Puertos. Actualmente desarrolla su actividad docente e investigadora en el Área de Estructuras y Materiales de la Escuela Universitaria Politécnica de La Almunia, centrada en el ámbito de la Resistencia de Materiales, Teoría de Estructuras e Ingeniería de los Materiales. Desarrolla trabajos de asistencia y asesoramiento técnico para consultoras de estructuras, principalmente en el ámbito de la rehabilitación estructural y en el cálculo de estructuras singulares. Cuenta con diversas publicaciones en revistas nacionales e internacionales relacionadas con el reciclado de materiales constructivos y sus aplicaciones estructurales.

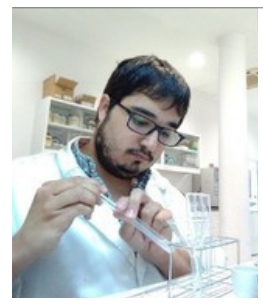

\section{Manuel Delgado del Valle}

manuel.delgado.delvalle@gmail.com

Ciencias Químicas. Universidad de Sevilla
Arboleda (Sevilla). Como doctorando de la Universidad de Zaragoza ha desarrollado actividad investigadora en el ámbito de la aplicación de las técnicas químicas al estudio de los procesos de deterioro del patrimonio monumental, especialmente en relación a las patologías asociadas a la precipitación de sales, destacando los estudios realizados en el Anfiteatro de Itálica (Santiponce, Sevilla) y en los monasterios de Santa Paula y la Cartuja (Sevilla), así como las colaboraciones con el IAPH en estudios previos para la restauración de distintos monumentos.

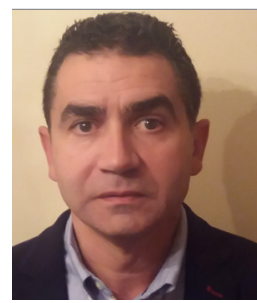

\section{Juan Carlos Sánchez Catalán}

jucasan@unizar.es

Escuela Universitaria Politécnica de la Almunia. Zaragoza

Doctor en Ingeniería del Medio Ambiente por la Universidad Alfonso X el Sabio (2013), desarrolla actualmente su actividad docente como profesor de Ingeniería de Materiales en la Escuela Universitaria Politécnica de La Almunia. Es miembro del Grupo de Investigación de Ingeniería Hidráulica y Ambiental, reconocido por el Gobierno de Aragón, desde 2017, donde continúa su actividad investigadora previa como miembro del Grupo de Investigación en Instrumentación y Modelización Aplicada, perteneciente al I3A (Instituto de Investigación de la Universidad de Zaragoza, 2013-2016). Ha desarrollado una intensa actividad investigadora como responsable de proyectos aplicados, destacando su labor como Director de I+D del Desafío Español Iberdrola en la Amerca'2 Cup ( (2005-2007) o como Director de I+D del nodo Tecnalia Research \& Innovation Aragón (20102011). En la actualidad es Director del Área de Negocio Tecnalia Research \& Innovation. Autor de varios artículos de investigación y de 4 patentes relativas a instrumentación científica.

Artículo enviado el 05/02/2018 Artículo aceptado el 04/06/2018

Licenciado en Química, Máster en Ciencia y Tecnología del Patrimonio Arquitectónico (UGR, 2012) y Máster en Formación del Profesorado de ESO, Bachillerato y FP (VIU, 2017). Actualmente desarrolla su actividad docente en el colegio 